\title{
SURVIVAL OF GIANT BUTTERCUP SEEDS BURIED AT DIFFERENT DEPTHS IN FOUR SOILS
}

\author{
T.K. JAMES and A. RAHMAN \\ AgResearch, Ruakura Research Centre, Private Bag 3123, Hamilton
}

\begin{abstract}
The viability of giant buttercup (Ranunculus acris) seed buried at three depths in four different soils in the Waikato region was evaluated over a 16 year period. Most seed buried in the top $2 \mathrm{~cm}$ soil layer disappeared within the first year. When buried at $4-6 \mathrm{~cm}$, numbers declined rapidly over the first two years and were no longer found at three of the four sites within 16 years. At the end of the study, up to $22 \%$ of the seed was still viable at the $19-21 \mathrm{~cm}$ depth. If left undisturbed and assuming exponential decay, it could take up to 51 years for deeply buried viable seed numbers to be reduced to $1 \%$ of the original number depending on soil type.
\end{abstract}

Keywords: giant buttercup, Ranunculus acris, buried seed, seed longevity, weed seed.

\section{INTRODUCTION}

Giant buttercup (Ranunculus acris) is an erect perennial buttercup growing to 1 $\mathrm{m}$ tall. It is found throughout New Zealand but is locally abundant in dairy pastures of the Takaka, Manawatu, southern Hawkes Bay and Waikato districts. In some locations this weed has become resistant to the phenoxy herbicides as a result of repeat spraying with MCPA (Bourdôt et al. 1990). As giant buttercup has only a weak vegetative method of propagation, seed is the most important route of dispersal and regeneration especially from small founder populations (Sarukhán and Harper 1973). Thus propagation by seed needs to be understood and allowed for when formulating weed management strategies (Popay and Thompson 1979; Forcella 1992).

Even with perennial plants, germination behaviour (i.e. the timing and pattern of germination and longevity of viable seed in the soil) is important because seedlings are more vulnerable to control methods than mature plants and therefore are better targets in any weed management system. Some weed species produce a more persistent soil seed bank than others (Thompson and Grime 1979). Two important factors that determine the persistence of the soil seed bank are seed burial depth and soil type (Forcella 1992; Roberts and Feast 1972). Differences in soil moisture, aeration, light and temperature within the soil profiles have a major influence on seed survival factors such as ageing processes, fungal parasitism and faunal predation (Buhler et al. 1998).

This paper reports on the results of an experiment aimed at evaluating the effect of burial depth on the viability of giant buttercup seed which was conducted at four field sites with similar climate but with varying soil characteristics.

\section{MATERIALS AND METHODS}

Four soil types representative of the main soils of the Waikato region were selected for this study (Table 1). The Horotiu and Dunmore soils are both well drained, the Hamilton clay loam is moderately well drained and the Rukuhia peat is very poorly drained. In June 1981 for each site, 90 sets of $250(0.31 \mathrm{~g})$ freshly gathered giant buttercup seed were each mixed with heat sterilised soil $(60 \mathrm{~g})$ collected from the site and 60 were put into fine nylon mesh bags $(0.25 \mathrm{~mm}$ mesh). Thirty tubes for each site ( $25 \mathrm{~cm}$ length of perforated, $6 \mathrm{~cm}$ diameter drainpipe) were filled with non-sterilised soil from the site. During this process, two seed/soil bags were placed in each tube at $4-6 \mathrm{~cm}$ and $19-21 \mathrm{~cm}$ from the top end of the pipe. The top $2 \mathrm{~cm}$ of the pipe was left

Proc. 52nd N.Z. Plant Protection Conf. 1999: 234-239 
free of soil and an unbagged seed/soil mixture was placed there, separated from the soil below by a layer of fine nylon mesh but uncovered at the top. These pipe sections were then buried vertically in the appropriate soil type with their tops flush with the soil surface in a regular $10 \times 3$ matrix at $20 \mathrm{~cm}$ centres. The burial sites were in permanent pasture that was regularly grazed or mown.

TABLE 1: Descriptions and some characteristics of the soils used for this study.

\begin{tabular}{lccccrc}
\hline & & & & & & \multicolumn{1}{c}{$\begin{array}{c}\text { Field } \\
\text { capacity }\end{array}$} \\
Soil & \% sand & \% clay & \% OC & pH & $\begin{array}{r}\mathrm{CEC}^{1} \\
\text { meq/100g }\end{array}$ & (\% v/v) \\
\hline Horotiu sandy loam & 61 & 15 & 8.7 & 5.4 & 37.4 & 44.8 \\
Dunmore silt loam & 54 & 17 & 9.5 & 5.5 & 51.7 & 66.7 \\
Rukuhia peat & 24 & 16 & 49.1 & 4.6 & 103.6 & 60.7 \\
Hamilton clay loam & 29 & 31 & 4.6 & 5.6 & 28.2 & 36.8 \\
\hline
\end{tabular}

${ }^{1} \mathrm{OC}=$ Organic carbon; $\mathrm{CEC}=$ Cation exchange capacity.

At 2 - 4 monthly intervals for the first 3 years after burial, emerged seedlings were counted and removed from the tops of the pipe sections. After 1, 2, 3, 5, 11 and 16 years, 3 randomly selected pipes were retrieved from each site in June or July and the viable seed from each depth counted. Seed viability was determined by germination in an unheated glasshouse. The contents of each nylon bag and the $0-2 \mathrm{~cm}$ layer were spread thinly $(2-4 \mathrm{~mm})$ on paper towels laid over damp vermiculite in a tray. At approximately monthly intervals, the emerged giant buttercup seedlings were counted and removed and the soil stirred. This procedure was repeated until no further seedlings emerged (4 - 6 months).

\section{RESULTS AND DISCUSSION}

The viability of the original seed (collected in autumn 1981), as determined by the Official Seed Testing Station, Palmerston North, was $43 \%$. This value was used to determine the initial number of viable seeds (108) buried at each depth.

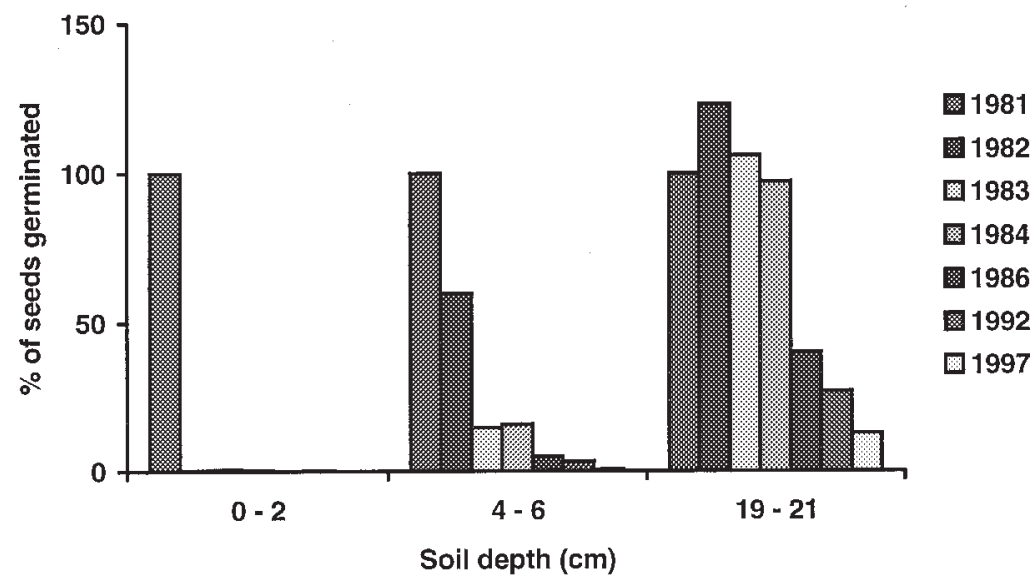

FIGURE 1: Giant buttercup seed which germinated after burial for different lengths of time at three depths in the soil, as a percentage of the viable seed originally present. Results averaged over four soil types. 
Results from the four sites show that seed viability was affected primarily by burial depth. The giant buttercup seed buried in the top $2 \mathrm{~cm}$ of the soil essentially disappeared within the first year, with only occasional single seeds germinating in subsequent years from the soil prepared in the glasshouse (Fig. 1). Much of the seed was lost through germination in spring of the first year (Fig. 2). In the Hamilton clay loam soil, germination accounted for nearly $50 \%$ of the viable seed while in the other three soils it accounted for about $20 \%$ of the seed. No seed germinated in the field during the second and third years. The remainder $(50-80 \%)$ of the viable seed in the top $2 \mathrm{~cm}$ remained unaccounted for. This suggests that under normal field conditions almost all of the seed that falls to the ground either germinates or is lost within the first year, unless it is quickly buried.

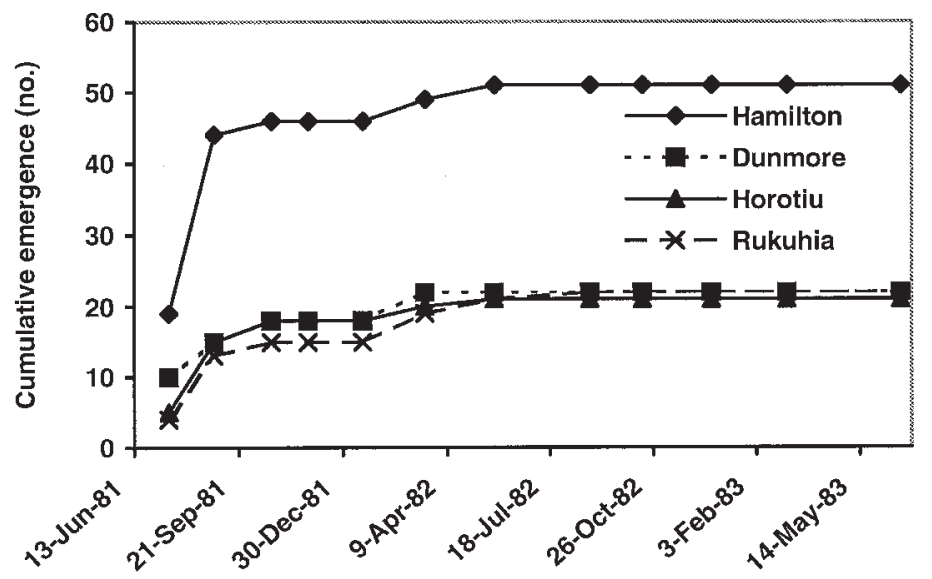

FIGURE 2: Cumulative emergence of giant buttercup from the $0-2 \mathrm{~cm}$ depth,
during the first 2 years, in four different soils (average of three
replicates).

The seed placed at the $4-6 \mathrm{~cm}$ depth disappeared from three of the sites within the study period and at the remaining site (Rukuhia peat) was reduced to less than $2 \%$ of the original viable seed (Fig. 3a). At the $19-21 \mathrm{~cm}$ depth, the amount of viable seed found at the end of the study ranged from $0.3 \%$ to $22 \%$ (Fig. 3b). At both depths seed disappeared fastest from the Hamilton clay loam soil and persisted longer in Rukuhia peat and Horotiu sandy loam soils.

The weed seed bank normally declines exponentially and this is readily explained in terms of biological processes (Thompson and Makepeace 1983; Rahman et al. 1998). Therefore an exponential model was used to examine these results and regression lines were fitted to logarithmic transformed data. From the regression equations the times for the amount of viable seed to be reduced to $1 \%$ of the original viable number were calculated and are presented in Table 2, together with the $\mathrm{R}^{2}$ of the fit. These data along with plotted results (Fig. 3) show that the decline of the giant buttercup seed at the $4-6 \mathrm{~cm}$ depth is not well explained by exponential decay. Rather it undergoes very rapid decline over the first 2 years followed by a period of more gradual decline (Fig. 1). Roberts and Boddrell (1985) report near complete depletion of giant buttercup seed from the top $7.5 \mathrm{~cm}$ layer of soil within 12 months of burial. This suggests that seeds are able to germinate throughout this depth. Thus, the initial rapid loss of seeds in our $4-6 \mathrm{~cm}$ layer could be a result of germination. At the $19-$ $21 \mathrm{~cm}$ depth, with the exception of the Rukuhia peat site, the decline in the seed bank more closely fitted an exponential decay. 

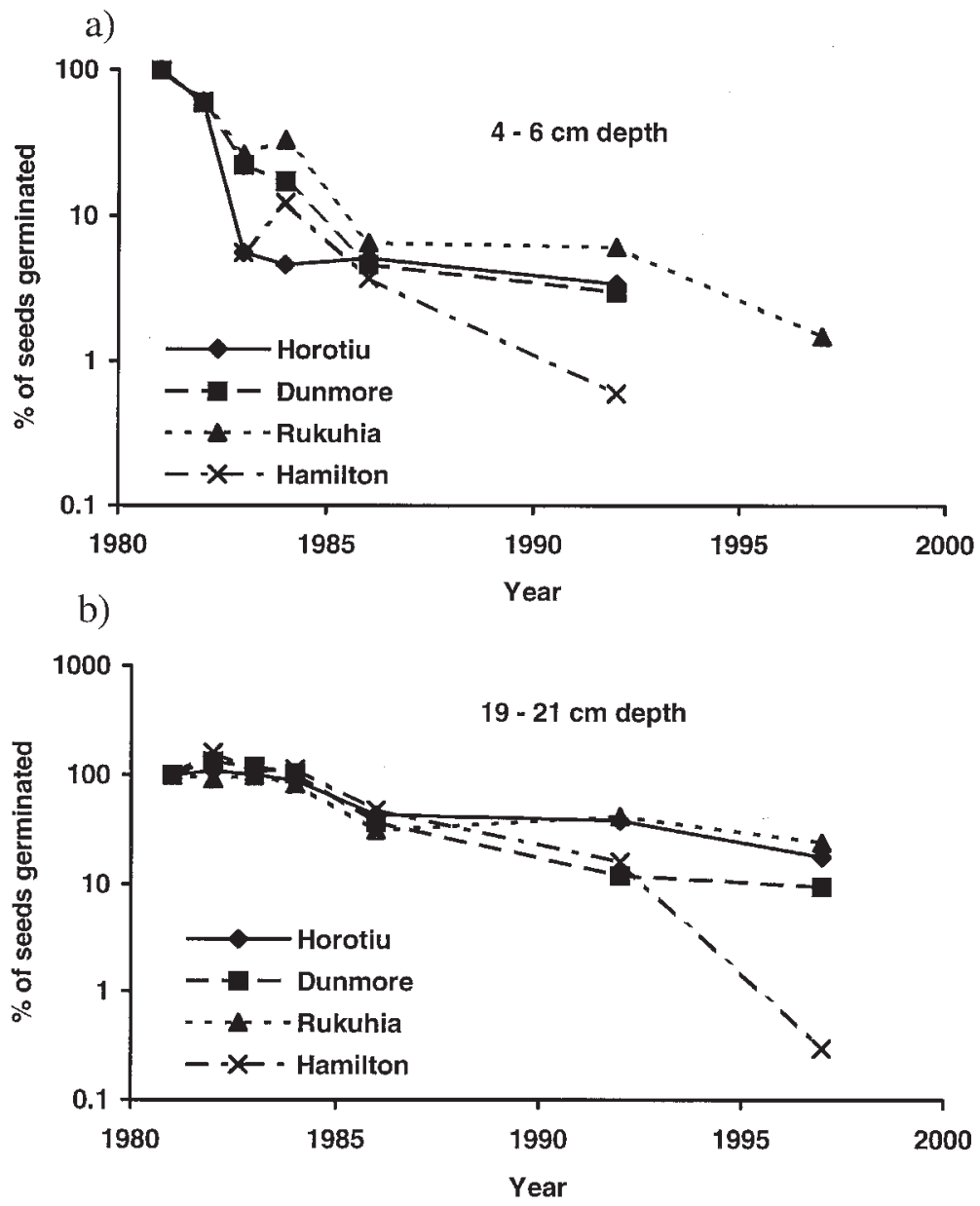

FIGURE 3: Percentage of the originally viable giant buttercup seed which germinated after being buried at (a) $4-6 \mathrm{~cm}$ and (b) $19-21 \mathrm{~cm}$ depths in four different soils (average of three replicates). A terminating line indicates that no seed germinated at the final sampling date.

TABLE 2: Predicted time (years) for the seed to reach $1 \%$ viability in the four soil types at two depths.

\begin{tabular}{|c|c|c|c|c|c|c|c|c|}
\hline \multirow{3}{*}{$\begin{array}{c}\text { Soil } \\
\text { depth } \\
(\mathrm{cm})\end{array}$} & \multicolumn{8}{|c|}{ Soil type } \\
\hline & \multicolumn{2}{|c|}{ Horotiu } & \multicolumn{2}{|c|}{ Dunmore } & \multicolumn{2}{|c|}{ Rukuhia } & \multicolumn{2}{|c|}{ Hamilton } \\
\hline & Years & $\mathrm{R}^{2}$ & Years & $\mathrm{R}^{2}$ & Years & $\mathrm{R}^{2}$ & Years & $\mathrm{R}^{2}$ \\
\hline $4-6$ & 12 & 0.75 & 13 & 0.81 & 18 & 0.87 & 9 & 0.83 \\
\hline $19-21$ & 42 & 0.92 & 27 & 0.91 & 51 & 0.76 & 15 & 0.88 \\
\hline
\end{tabular}


The short persistence of viable giant buttercup seed in the surface layer of the soil is supported by the findings of Sarukhán (1974) and Roberts and Boddrell (1985) who found that the seed population would be almost depleted by the time newly-produced seeds are added to the seed bank. Clearly, in the absence of fresh seed input in the top layer of the soil, it only takes a few months for the seed bank to decline to low levels. However, if the seed is quickly buried to $20 \mathrm{~cm}$, (by worms, falling down cracks or by cultivation) then it could take up to 50 years for seed viability to decline to less than $1 \%$. Under normal practices very little seed is likely to be rapidly buried to this depth and this would explain the small size of the naturally occurring seed bank found by Sarukhán (1974). Sarukhán (1974) also found that creeping buttercup (R. repens) seed was more persistent in the soil than giant buttercup seed. Thus, the short persistence of giant buttercup seed in the soil is possibly one reason why this species is not as widely dispersed as some other Ranunculus spp. in New Zealand.

In this study the estimate of the longevity of the seed buried at the $4-6$ and $19-$ $21 \mathrm{~cm}$ depths is possibly overestimated as the seed/soil mix was enclosed in a nylon mesh bag, excluding some important predators such as earthworms. Also, the determination of the viability of the original seed appears to be conservative as this was exceeded by germination of the field samples from the $19-21 \mathrm{~cm}$ depth in the first 2 years after burial (Fig. 1). If the highest field germination (69\% in Hamilton clay loam) is used as the base for percent viability then the estimates of time for the seed bank to reduce to $1 \%$ of the original viable seed would be around $10 \%$ shorter than those presented in Table 2.

Giant buttercup seed retained greater viability in the Rukuhia peat and Horotiu sandy loam soils, and least viability in the Hamilton clay loam (Fig. 3) while the Dunmore silt loam was intermediate. The Hamilton clay loam soil has a heavier texture, lower water holding capacity (Table 1) and is more prone to drying and these characteristics are probably associated with the more rapid depletion of the weed seed. In an associated study, nodding thistle (Carduus nutans) seed also disappeared fastest from the Hamilton clay loam soil (James et al. 1998). However, the overall persistence of nodding thistle seed was longer in all the soils.

The rapid disappearance of giant buttercup seed from the top layer of soil means that long term control of this weed should be readily attainable if seed production is eliminated before the plants are killed. It also demonstrates the importance of effective control of this weed in newly sown pastures, where soil cultivation has brought old but viable seed to the surface, and not allowing new seed to be produced.

\section{ACKNOWLEDGEMENTS}

The authors wish to thank Alex Thompson who carried out the seed burial and collected the data for the first five years.

\section{REFERENCES}

Bourdôt, G.W., Hurrell, G.A. and Saville, D.J., 1990. MCPA-resistance in giant buttercup (Ranunculus acris) in North Island dairy pastures. Proc. $43 \mathrm{rdN}$.Z. Weed and Pest Control Conf:: 229-232.

Buhler, D.D., Hartzler, R.G. and Forcella, F., 1998. Weed seed bank dynamics: implications to weed management. J. Crop Production 1: 145-168.

Forcella, F., 1992. Prediction of weed seedling densities from buried seed reserves. Weed Res. 32: 29-38.

James, T.K., Rahman, A., Wardle, D.A. and Bonner, K.I., 1998. Survival of nodding thistle (Carduus nutans) seed buried at different depths in four soils. Proc. 51st N.Z. Plant Prot. Conf: : 33-37.

Popay, A.I. and Thompson, A., 1979. Some aspects of the Biology of Carduus nutans in New Zealand pastures. Proc. 7th Asian-Pacific Weed Sci. Soc. Conf.: 343-346.

Rahman, A., James T.K., Bourdot, G. and Grbavac, N., 1998. Weed seedbank estimation, spatial distribution, decline and potential for predicting future weed populations. Plant Prot. Quarterly 13(4): 1-6. 
Roberts, H.A. and Boddrell, J.E., 1985. Seed survival and seasonal emergence in some species of Geranium, Ranunculus and Rumex. Ann. Appl. Biol. 107: 231-238.

Roberts, H.A. and Feast, P.M., 1972. Fate of seeds of some annual weeds in different depths of cultivated and undisturbed soil. Weed Res. 12: 316-324.

Sarukhán, J., 1974. Studies on plant demography: Ranunculus repens L., R. bulbous L., R. acris L. II Reproductive strategies and seed population dynamics. J. Ecol. 62: 151-177.

Sarukhán, J. and Harper, J.L., 1973. Studies on plant demography: Ranunculus repens L., $R$. bulbous L., R. acris L. I. Population flux and survivorship. J. Ecol. 61: 675-716.

Thompson, K. and Grime, J.P., 1979. Seasonal variation in the seed banks of herbaceous species in ten contrasting habitats. J. Ecol. 67: 893-921.

Thompson, A. and Makepeace, W., 1983. Longevity of buried ragwort (Senecio jacobaea L.) seed. N. Z. J. Exp. Agr. 11: 89-90. 